\title{
The dissociation of position and extent in Müller-Lyer figures
}

\author{
ARIEN MACK, FRIDERIKE HEUER, KATHERINE VILLARDI, and DEBORAH CHAMBERS \\ New School for Social Research, New York, New York
}

\begin{abstract}
Three experiments were designed to determine whether Müller-Lyer figures cause a misperception of the positions of their fins and, if they do, whether it is commensurate with the distortion of extent. Observers marked the visible intersection of shaft and fins either with their unseen hands or with their visible hands after the figure had been removed from view. In the former case, no systematic distortions of position were evident. In the latter case, there were small, systematic distortions of position, which were significantly smaller when the observers fixated the target vertex than when they fixated the center of the figure. These differences are discussed in terms of the probable similarities between the control of eye movements and the control of pointing responses. Of particular importance is the finding that even the largest distortions of vertex position were much smaller than the distortions of shaft extent. The results appear to provide evidence of the independence of perceived position from perceived extent in Müller-Lyer figures and to contradict all existing theories of the illusion.
\end{abstract}

The Müller-Lyer (M-L) illusion is routinely classified as an illusion of extent in which the shaft, or separation, between the outgoing fins is perceived as longer than the shaft between the ingoing fins. Despite the fact that it is by far the most studied of all geometric illusions, there seems to have been no full-scale investigation or clear answer to the question of whether the misperception of extent is associated with a correlative misperception of the positions of the intersections between shafts and fins. In fact, what evidence there is is confusing.

A number of reports suggest the presence of an appropriate position error. For example, Benussi (1912) reported that sequential, stroboscopic presentations of a series of M-L-like figures (see Figure 1) might produce the impression that the midpoint of the line that was actually bisected by the obliques and horizontals was gliding up and down as the orientations of the bisecting lines changed. Judd (1899) reported that "if an oblique line ends in a horizontal line which extends for an indefinite distance on each side of the point of meeting ... [and] if the point of intersection is taken as the point of greatest importance, the illusion will take the form of the shifting of that point towards the extremity of the horizontal line which is on the acute angle side" (p. 245); (see Figure 1). Judd (1898) also reported that when leftward- and rightward-pointing arrows of equal length were vertically aligned, the leftward-pointing arrow appeared displaced

This research was supported by NSF Grant BNS 83-10811. We wish to express our gratitude to Professor Barbara Gillam for a preliminary discussion of some of the issues raised by these experiments, and our appreciation to Professor Daniel Reisberg for writing the programs for the displays used in Experiments 2 and 3.

The authors' mailing address is: The Graduate Faculty, New School for Social Research, 65 Fifth Ave., New York, NY 10003. to the right of the rightward-pointing one (see Figure 1). On the other hand, the Morinaga paradox, named after the investigator who first described it (Morinaga, 1941; see also Day, Bellamy, \& Norman, 1983; Morinaga \& Ikeda, 1965; Restle, 1976), suggests an opposite displacement of vertex position (see Figure 1). Instead of outward fins' appearing displaced away from each other, they appear displaced towards each other, and the reverse is true of ingoing ones. In fact, the occurrence of this phenomenon led Coren and Girgus (1978) to speculate that "the judgments of locus and the judgments of extent may be independent"' (p. 61), although, in an earlier statement, they appear to assert the opposite: "To alter the apparent extent of a line, we must alter the location of its end points"' (p. 59).

Perhaps, because we typically assume that there is a necessary connection between position and extent, we automatically infer that any alteration of one entails an equivalent alteration of the other. Certainly, in Euclidean descriptions of space, where extent is defined as the distance between two spatial loci, if extents differ, the positions of these loci must differ as well. In fact, this may be the primary reason why the question of whether $M-L$ figures engender misperceptions of vertex positions has not been actively pursued, even though at least two proposed explanations of the illusion assume that it does. If the illusion is caused either by optical blurring or by neural displacement of contours at the intersection of shaft and fins, then the positions of the vertices must be systematically mislocalized. (The reader is referred to Coren \& Girgus, 1978, pp. 77-94, for a review of these accounts of the illusion).

There are, however, theoretical grounds to question whether the misperception of extent, characteristic of the M-L illusion, is associated with a correlative mispercep- 


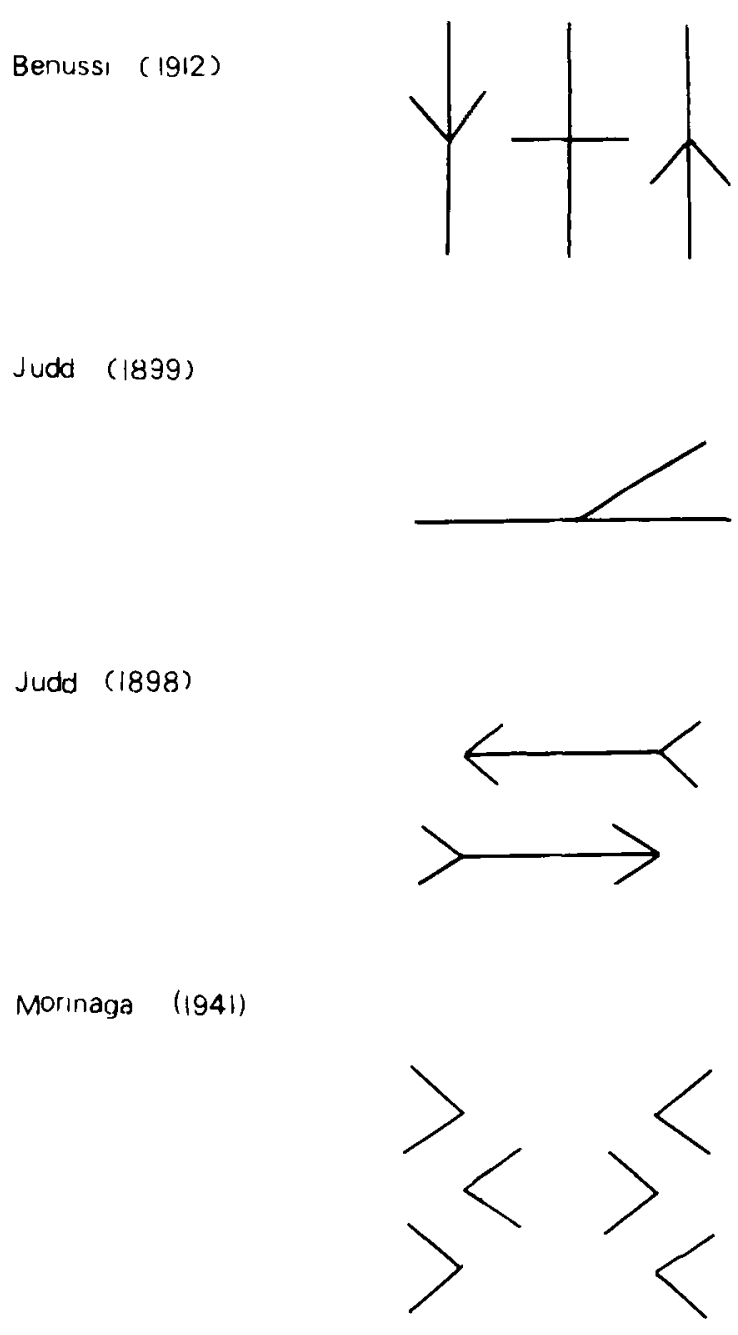

Figure 1. Variations of Müller-Lyer figures suggesting vertex displacement.

tion of vertex position. First, spatial attributes bound together in Euclidean space are not necessarily bound together in perceptual space. For example, even though motion is defined as the change of position over time, the perception of motion need not entail the perception of any change in position. This occurs whenever perceived motion is the result of a motion aftereffect. Second, the determinants of perceived extent are not the same as the determinants of perceived position, so that stimulus configurations that affect one need not affect the other.

Egocentric position, defined as the position of a stimulus in relation to the head of an observer, is specified by information about the position of its image on the retina and the position of the eyes in the head. Exocentric or object-relative position is specified by the position of the stimulus in relation to some other visual object. On the other hand, egocentric extent is specified by the visual angle subtended by the imaged object and information about the distance of the object from the observer, whereas exocentric extent is specified by the extent of the object in relation to the extent of another, generally surrounding object. The fact that perceived position and perceived extent are based on very different sources of information surely implies that the misperception of one need not entail the other.

The only experiments that seem directly relevant to the question of whether $M-L$ figures engender misperceptions of vertex positions would appear to be those designed to determine whether the M-L illusion can be attributed to either actual or intended eye movements. These experiments typically have required observers to scan between the vertices of $M-L$ figures while their eye movements were monitored. Since the saccadic eye movements that enable the eye to scan from one vertex to another are programmed in terms of the position of the eye-movement target, these eye movements might be expected to reflect a position distortion, if there is one. The evidence that eye movements across the apparently longer configuration tend to be of greater amplitude than eye movements across the apparently shorter configuration (Boyce \& West, 1967; Delbarre, 1897; DeSisto \& Moses, 1968; Festinger, White, \& Allyn, 1968; Judd, 1905; Yarbus, 1967), which has been taken as support for an eyemovement account of the illusion, appears to demonstrate an appropriate misperception of vertex positions in $\mathrm{M}-\mathrm{L}$ figures. There are, however, at least two reasons to question this conclusion.

First, there are reports that indicate that M-L figures do not predictably produce eye-movement errors. Stratton (1906) failed to find any consistent relationship between eye movements and the illusion in $37 \%$ of the cases he examined. Boyce and West (1967), who found the "expected" difference in horizontal saccades between the vertices of either the "long" or "short" figure, failed to find any eye-position errors when the saccade was between vertically aligned vertices of the "short" and "long" figures. If there were a misperception of vertex position, this should have been evident here as well. Finally, Wong (1981), using a highly precise eye-movement monitoring system, found no position errors when observers were urged to saccade as accurately as possible between the vertices of M-L figures, although predictable differences were obtained when accuracy was not stressed and the instructions resembled those used by other investigators. ${ }^{1}$

The remaining reason why the eye-movement data are questionable derives from recent evidence that perceived position has no influence over either pursuit or saccadic eye movements when a visible eye-movement target is present (Mack, Fendrich, \& Chambers, 1982; Mack, Fendrich, \& Wong, 1982; Wong \& Mack, 1981). ${ }^{2}$ Thus, even if a M-L configuration were to induce a misperception of vertex position, there is reason to doubt whether it would be revealed by errors in the positioning of the eyes.

The first experiment examined the question of whether M-L figures induce a misperception of the positions of its vertices by requiring observers to point to each of the vertices of the figure while their pointing arms were not 
visible. ${ }^{3}$ If the position of the vertex was mislocated, openloop pointing would be expected to err in the direction of the illusion. In other words, the apex of an ingoing fin should be located inward of its true position, whereas the reverse should be true of the vertex of an outgoing fin. In this experiment and in the others described subsequently, standard estimates of the illusion were always obtained. This permitted an estimation of the degree to which any mislocalization of the vertices was commensurate with the misperception of extent. If they were fully commensurate, then the distortions of vertex positions should, when summed, be equal to the distortion of extent and the calculated magnitude of the illusion derived from pointing should be equivalent to that derived from judgments of extent.

\section{EXPERIMENT 1}

\section{Method}

Subjects. Ten observers with normal or corrected-to-normal vision were recruited from the New School population and paid for participation in this study. No observer had previously participated in a M-L study.

Apparatus. The Brentano version of the M-L illusion, constructed of narrow $(1.3-\mathrm{cm})$ white tape affixed to a black cardboard rectangle, served as the test figure (see Figure 2). It was presented within a wooden box placed $45.7 \mathrm{~cm}$ from the observer. At this distance, $.93 \mathrm{~cm}$ subtends $1^{\circ}$ of visual angle. Each arrow tip formed a $60^{\circ}$ angle, which was bisected by the horizontal shaft. The length of the shaft between the outgoing arrow heads (labeled A and B in Figure 2) was fixed at $15.24 \mathrm{~cm}$, and the positions of vertices $A$ and $B$ were also fixed. The length of the shaft between vertices $B$ and $C$ and the position of vertex $C$ were adjustable as a unit. The distance between vertices $B$ and $C$ could be as small as $2.54 \mathrm{~cm}$ or as great as $30 \mathrm{~cm}$. This adjustment was possible because vertex $C$ and all but $2.54 \mathrm{~cm}$ of the shaft between vertices $B$ and $C$ were mounted on a movable track, also made of black cardboard. The edge of the stationary black cardboard rectangle on which the stationary part of the display was mounted was flush with the black rectangle on which the movable part of the display was mounted, so that any adjustment of line segment B-C caused its mount to slide easily underneath or out from under the mount for line segment A-B.

The control figure, mounted on identical black cardboard, was a duplicate of the illusion figure, except that the fins were vertical lines, $8.4 \mathrm{~cm}$ long, that bisected the horizontal shaft. The control

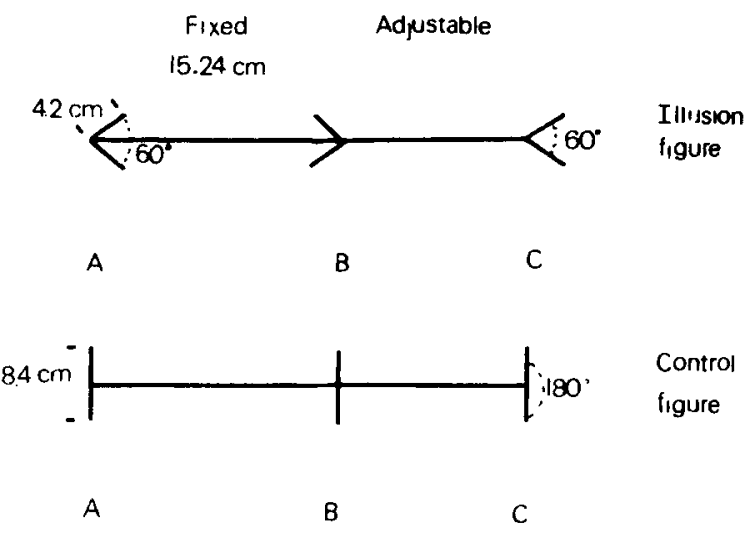

Figure 2. Scheme of apparatus for Experiment 1. display was slipped on top of the illusion figure and held securely in place when it was presented to the observers.

A horizontal platform extended out from the display $1.3 \mathrm{~cm}$ below the lower tips of the figures. Its purpose was to conceal the hand and arm that the observer used for pointing. Calibrated graph paper, carefully and rigidly mounted $1.9 \mathrm{~cm}$ below the visual display, was also concealed by the platform. The graph paper served as the marking surface for the pointing task.

Procedure. Prior to testing, the observer was seated at the table on which the display and occluding platform were placed, and was shown the illusion figure set, so that the length of shaft B-C was equal to shaft A-B. The observer was told that he or she was to point, as accurately as possible, to the exact positions of the intersections between arrowheads and shaft. This was to be done with a colored pen on paper placed directly below the figure. The observer was instructed to reach below the platform, to mark accurately, and then to return the hand to his or her lap. A differently colored pen was used to mark each of the three vertices. Each vertex was marked four times in random order, and vertex position was taken to be the mean of these four marks.

After the 12 pointing trials, estimates of the illusion were obtained. The observer was asked to tell the experimenter how to adjust line B-C so that it appeared equal in length to line A-B. There were four such trials. On half of them, line segment B-C was initially extended to its maximum, and on half it was reduced to its minimum. At the conclusion of these trials, the observer left the experimental room briefly while the control figure was properly positioned. The observer then returned to the laboratory, and the entire procedure was repeated with the control figure.

\section{Results}

As expected, the $\mathrm{M}-\mathrm{L}$ configuration generated a strong illusion of extent. The mean adjustment of line segment $B-C$ perceived to be equal in length to $A-B$, which was fixed at $15.24 \mathrm{~cm}$, was $11.15 \mathrm{~cm}(\mathrm{SD}=.43 \mathrm{~cm})$. For the control figure, the mean length of line B-C that appeared equal to segment $\mathrm{A}-\mathrm{B}$ was $15.29 \mathrm{~cm}$ (SD = $.71 \mathrm{~cm})$. This difference was significant $[F(1,9)=317$, $\mathrm{p}<.01]$. The magnitude of the illusion, calculated with the formula (Illusion - Control)/Control, was a robust $27 \%$.

The results from the pointing (marking vertices) task were strikingly different. Table 1 presents the mean deviations from accuracy of the markings of the three vertices for both the illusion and control figures. If the $M-L$ figure induces a misperception of the positions of the intersections of shafts and fins, the markings of vertices $A$ and $C$ should deviate to the right of their actual positions, whereas the markings of vertex B should deviate to the left. In contrast, deviations in the markings of the vertices of the control figure should be random. If the markings of the control figure are treated as indicators of the accuracy with which observers are able to point to visible targets without sight of their hands, then the markings of vertices $A$ and $C$ of the illusion figure should be to the right of the comparable markings of the control figure and the reverse should be true for the markings of vertex B. Contrary to these predictions, a one-way ANOVA of these data indicated that there were no significant differences $[F(2,18)=.495)$ among comparable control and illusion figure vertices, and a comparison of the mean deviations around each of the comparable vertices confirmed this. (The $t$ for the deviations around ver- 
Table 1

Mean Deviations (in Centimeters) from Accurate Pointing to Figure Vertices as a Function of Figure Type

\begin{tabular}{|c|c|c|c|}
\hline Figure Type & Vertex A & Vertex B & Vertex C \\
\hline$\underset{\mathrm{A}}{\stackrel{\text { B }}{\text { Illusion }}} \stackrel{\mathrm{C}}{<}$ & $\begin{array}{l}-1.05 \\
(2.00)\end{array}$ & $\begin{array}{l}-.58 \\
(.58)\end{array}$ & $\begin{array}{c}+.64 \\
(1.55)\end{array}$ \\
\hline$\left.\right|_{\mathbf{A}} ^{\text {Control }}$ & $\begin{array}{l}-2.09 \\
(1.45)\end{array}$ & $\begin{array}{c}+.24 \\
(1.03)\end{array}$ & $\begin{array}{c}+.99 \\
(1.32)\end{array}$ \\
\hline
\end{tabular}

Note-Standard deviations are in parentheses. - Indicates deviations to left of vertex. + Indicates deviations to right of vertex.

tex $\mathrm{A}=.906$; around vertex $\mathrm{B}, \mathrm{t}=2.1$; and around vertex $C, t=1.4$.) In fact, only the mean difference between the illusion and control markings of vertex $B$ was even in the predicted direction.

These results suggest a complete dissociation between perceived position and extent in M-L configurations, although at least one other explanation must be considered. Benussi (1904) reported that if observers adopt what he referred to as a "part isolating" attitude toward the illusion figure, the illusion is significantly reduced in contrast to the illusion obtained when the observer has what he referred to as a "whole perceiving" attitude. This seems to be confirmed by Coren and Porac (1983) and Rock (1984), who demonstrated that any alteration in the M-L configuration that facilitates a segregation of fins and shaft (i.e., part isolation) reduces the illusion. Requiring observers to point to a vertex might facilitate fin isolation, and this may have reduced the illusion relative to that revealed by measures of perceived extent which were more likely to have engendered a "whole perceiving" attitude. If this is what occurred, then the distortions of perceived position might have been small enough to have been obscured by the variability in the pointing responses.

The next experiment explored this possibility. The experiment was based on the assumption that controlling the locus of fixation would most effectively control the way in which the figures were observed during the localization task. We reasoned that it would be more difficult to effectively isolate the vertex to be marked if the observers viewed either the "long" or "short" half of the configuration by itself while fixating midway between the two vertices. On the other hand, fixation upon the vertex itself should facilitate vertex isolation. If control of the fixation position has the predicted effect on the magnitude of the illusion and there is a distortion of position, then there should be larger pointing deviations in the direction of the illusion when the center is fixated than when the vertex is fixated. Fixation position was also manipulated during extent judgment trials, although it was more difficult to predict what the effect of this might be, since fixating on a vertex while having to estimate extent might not engender the appropriate part-isolating, illusionreducing attitude.

\section{EXPERIMENT 2}

\section{Method}

Subjects. Twenty-four observers were paid for participation in this study; none had ever previously participated in a $\mathrm{M}-\mathrm{L}$ experiment.

Display and Procedure. The display, generated and controlled by a Commodore 64 microcomputer, was presented on a TV monitor. An observer viewed the display from a distance of $35.6 \mathrm{~cm}$ while his or her head was maintained in position by a chinrest. At this distance, $1.24 \mathrm{~cm}$ subtends $1^{\circ}$ of visual angle. At the beginning of a trial, a fixation point was displayed on the monitor, located either where a vertex of a figure would subsequently appear or midway between the two vertices of the subsequently displayed figure. When the observer indicated fixation of this point, it disappeared and was immediately replaced by one of the following figures: the "short" half of the M-L configuration with ingoing fins, the "long", half with outgoing fins, or the control figure with vertical lines at either end. The horizontal shaft separating the fins or the vertical lines was $6 \mathrm{~cm}$. The angle between shaft and fin of the M-L figures was $20^{\circ}$, and each fin was $2.87 \mathrm{~cm}$ long. The vertical lines at both ends of the control shaft were also $2.87 \mathrm{~cm}$ long. The stimulus figures were imaged on a dark gray screen and were visible for only $183 \mathrm{msec}$. The briefness of the presentation prevented the observer from moving his or her eyes over the figure. Immediately following the presentation of the figure, the screen became white, erasing or masking any afterimage of the figure.

Immediately after the figure disappeared, the observer marked, with a fine-tip felt pen directly on the screen, the apparent position of either the right or left vertex. On trials in which observers fixated a vertex, he or she marked that vertex. On trials in which the center of the figure was fixated, he or she was told prior to figure presentation which vertex to mark.

On the extent-judgment trials, a $10.4-\mathrm{cm}$ horizontal line appeared on the screen immediately after the white mask. This line was displayed $3.1 \mathrm{~cm}$ below the shaft of the previously presented figure, and one of its ends was aligned with that figure's midpoint. Whether this line extended to the right or left was varied randomly from trial to trial. When it appeared, the observer indicated the apparent length of the shaft of the previously viewed figure by marking off an equivalent segment on the line, using the end centered on the screen as the point of origin.

At the end of each trial, the observer turned away from the screen and the experimenter measured and recorded either the exact position of the vertex mark or the exact length of the marked line segment. The observer was asked to mark both vertex position and shaft extent as precisely as possible. There were a total of 24 vertexposition-marking trials and 18 extent-judging trials. The position trials consisted of eight presentations of each of the three figures ("short," "long," and control), with the fixation point located at the left vertex on two trials, at the right vertex on two trials, and at center on four trials. On center-fixation trials, the right vertex was marked twice and the left vertex was marked twice. The order of these trials was randomized.

In order to avoid any decrement in illusion strength caused by prolonged viewing of the figure, the 18 extent-judgment trials followed the position-marking trials. These trials consisted of six presentations of each of the three stimulus figures, with the fixation point located twice at the right, twice at the left, and twice at center. The order of these trials was also random.

\section{Results}

Even though the stimulus figures were visible for less than 200 msec on any one trial, a substantial extent illusion was perceived. Table 2 presents the observers' mean estimates of the length of each of the three figures while 
Table 2

Mean Perceived Extents (in Centimeters) and Mean Perceived Illusion as a Function of Figure Type and Fixation Position

\begin{tabular}{|c|c|c|c|c|}
\hline \multirow[b]{3}{*}{ Figure Type } & \multicolumn{4}{|c|}{ Fixation Position } \\
\hline & \multicolumn{2}{|c|}{ Vertex } & \multicolumn{2}{|c|}{ Center } \\
\hline & Extent & $\%$ Illusion & Extent & $\%$ Illusion \\
\hline $\begin{array}{l}\text { Short } \\
\leftrightarrow\end{array}$ & $\begin{array}{l}4.98 \\
(.73)\end{array}$ & $12.01 \%$ & $\begin{array}{r}4.71 \\
(.94)\end{array}$ & $11.30 \%$ \\
\hline$\stackrel{\text { Long }}{>}$ & $\begin{array}{l}7.03 \\
(.86)\end{array}$ & $24.20 \%$ & $\begin{array}{c}6.87 \\
(1.01)\end{array}$ & $29.38 \%$ \\
\hline Control & $\begin{array}{l}5.66 \\
(.75)\end{array}$ & & $\begin{array}{l}5.31 \\
(.71)\end{array}$ & \\
\hline
\end{tabular}

Note-Standard deviation are in parentheses. Actual extent $=6 \mathrm{~cm}$.

fixating the center or the right or left vertex. The table also includes the calculated mean size of the illusion, with center and vertex fixation. There was a mean overestimation of the "long" figure relative to the control figure of $29 \%$ and a mean underestimation of the "short" figure relative to the control of $13 \%$ when the center was fixated. There was a mean $25 \%$ enlargement of the "long" figure and a $12 \%$ decrease in the "short" figure when the vertex was fixated. (The finding that the "long" figure produced a greater distortion of extent than the "short" figure regardless of gaze direction is consistent with previous findings.) A two-way ANOVA of these data indicated that both stimulus type $[\mathrm{F}(2,46)=110.15, \mathrm{p}<.001]$ and location of fixation $[F(1,23)=17.46, p<.01]$ significantly affected the judgments of extent. However, the fact that there was no significant interaction between these factors $[\mathrm{F}(2,46)=1.2]$ means that fixation position did not differentially affect the judgments of extent in the M-L and control figures. Rather, for reasons that are not clear, fixating the center as opposed to fixating a vertex consistently resulted in smaller estimates of shaft extent for all three figures.

The mean deviations from accurate pointing to the vertices obtained when the center and a vertex were fixated are reported in Table 3 . The central questions that these data address were: (1) Are there predictable distortions of vertex positions with M-L figures? (2) If distortions occur, are they less with vertex than with center fixation? And finally, (3) if distortions occur, are they commensurate with the distortions of perceived extent? Positive answers to the first two of these questions are provided by the outcomes of a two-way ANOVA of the pointing results in which stimulus type and fixation position were the main factors. Both main factors and their interaction proved to be significant [for stimulus type, $F(2,46)=$ $39.6, \mathrm{p}<.001$; for fixation position, $\mathrm{F}(1,23)=10.07$, $p<.001$; and for the interaction, $F(2,46)=4.05$, $p<.01]$. The significant effect of stimulus type on pointing is a function of the fact that the mean deviations around comparable vertices of the "short" and "long" figures were in opposite directions regardless of fixation position. In each instance, the mean deviation from accurate location is consistent with an outward displacement of the vertices of the "long" figure and an inward displacement of the vertices of the "short" figure. Thus, there were predictable distortions of vertex positions in the M-L figures. This was borne out by post hoc comparisons between mean deviations of comparable vertices of illusion and control figures. In every instance, these differences were significant and in the correct direction.

The significant interaction between stimulus type and fixation position permits a positive answer to the question of whether fixation position affects the localization of the vertices of $\mathrm{M}-\mathrm{L}$ figures, since this interaction suggests that the effect of fixation position differed, depending on stimulus type. In fact, center fixation magnified the deviations around the vertices of the $\mathrm{M}-\mathrm{L}$ figures more than around the vertices of the control figure, and this is consistent with the speculation that center fixation enhances the illusion. Thus, although center fixation produces greater pointing errors overall, it did so more with illusion than with control figures.

The significant main effect for fixation position reflects the fact that it is easier to point accurately to where one is looking than to some other place, so that, regardless of stimulus type, deviations were significantly greater with center fixation than with vertex fixation.

To answer the third question, that about the commensurability of the distortions of position and extent, it was necessary to transform the position data so that they would be directly comparable to the judged extents. This was done by inferring extents from the vertex position data. An observer's mean deviations around the left and right vertices of each figure were added to or subtracted from the actual shaft length. If the mean deviation was outward of the actual vertex position (plus in Table 3), it was added to $6 \mathrm{~cm}$, the actual shaft extent, and if it was inward (minus in Table 3), it was subtracted. The results of these calculations were then directly compared with the estimates of extent obtained on trials in which the task involved judging extent. This comparison was made by means of a three-way ANOVA in which stimulus type (long, short, control), fixation position (center, vertex), and task (pointing, marking extent) were the main factors. The outcome of this analysis is recorded beneath

Table 3

Mean Deviations (in Centimeters) from Accurate Pointing to Figure Vertices as a Function of Fixation Position and Figure Type

\begin{tabular}{|c|c|c|c|c|c|c|}
\hline \multirow[b]{3}{*}{ Fixation Position } & \multicolumn{6}{|c|}{ Figure Type } \\
\hline & \multicolumn{2}{|c|}{$\begin{array}{l}\text { Short } \\
\leftrightarrow\end{array}$} & \multicolumn{2}{|c|}{$>^{\text {Long }}$} & \multicolumn{2}{|c|}{ Control } \\
\hline & $\begin{array}{c}\text { Left } \\
\text { Vertex }\end{array}$ & $\begin{array}{c}\text { Right } \\
\text { Vertex }\end{array}$ & $\begin{array}{c}\text { Left } \\
\text { Vertex }\end{array}$ & $\begin{array}{l}\text { Right } \\
\text { Vertex }\end{array}$ & $\begin{array}{c}\text { Left } \\
\text { Vertex }\end{array}$ & $\begin{array}{c}\text { Right } \\
\text { Vertex }\end{array}$ \\
\hline Center & $\begin{array}{c}.2 \\
(.47)\end{array}$ & $\begin{array}{c}.36 \\
(.48)\end{array}$ & $\begin{array}{c}-.4 \\
(.49)\end{array}$ & $\begin{array}{c}-.1 \\
(.38)\end{array}$ & $\begin{array}{c}-.02 \\
(.4)\end{array}$ & $\begin{array}{c}.26 \\
(.35)\end{array}$ \\
\hline Vertex & $\begin{array}{c}.02 \\
(.24) \\
\end{array}$ & $\begin{array}{c}.09 \\
(.25) \\
\end{array}$ & $\begin{array}{l}-.24 \\
(.3) \\
\end{array}$ & $\begin{array}{c}-.11 \\
(.25)\end{array}$ & $\begin{array}{l}-.02 \\
(.25)\end{array}$ & $\begin{array}{c}.03 \\
(.17)\end{array}$ \\
\hline
\end{tabular}

Note-Standard deviations are in parentheses. - indicates deviations beyond figures, e.g., $-><-.+$ indicates deviations within figures, e.g., $\stackrel{+}{+}<$. 


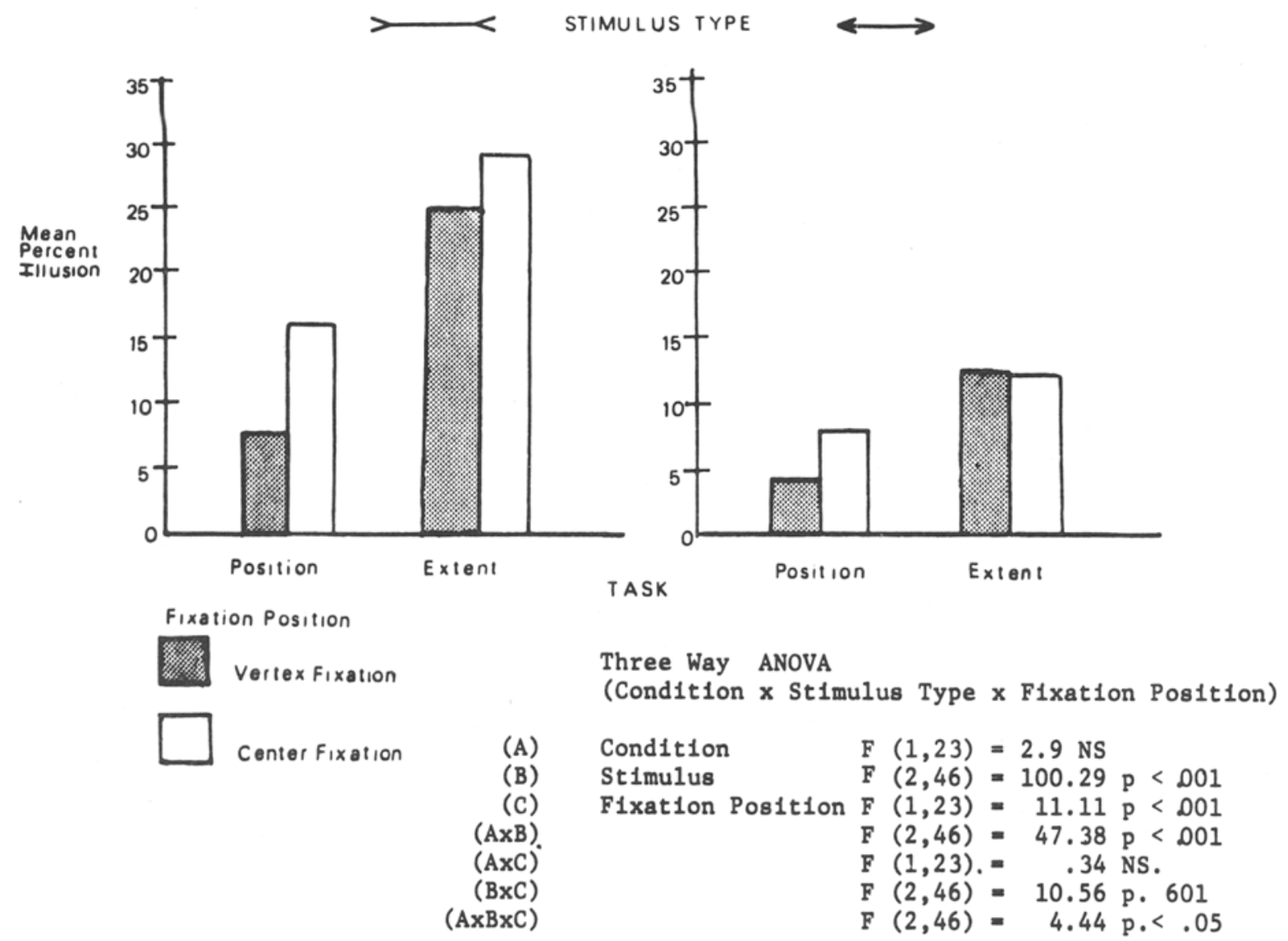

Figure 3. Mean percent illusion as a function of fixation position and task in Experiment 2.

Figure 3, in which the mean percent illusion obtained in the several conditions of this experiment are graphed. Consistent with our initial speculation, fixation position had a significantly greater impact on pointing than on judging extent. (This is revealed both by the significant interaction between fixation position and task and by inspection of Figure 3). Vertex fixation tended to reduce the distortions of both inferred and obtained extents, but this reduction was significantly greater in the pointing task.

The outcome of the ANOVA most relevant to the question of whether the distortions of position and extent were comparable is the highly significant interaction between stimulus type and judgment condition. This interaction indicates that the distortions of position and extent were not comparable, and inspection of Figure 3 suggests that the reason for this is that the distortions of extent that occurred when extent was judged were consistently and substantially larger than the distortions that occurred when vertex position was marked. Thus, on the basis of this evidence, we conclude that position and extent are independent of each other. Moreover, this conclusion receives further support from an analysis of the degree of correlation between extents inferred from a given sub- ject's pointing responses under one particular viewing condition and the extents obtained when extent was directly judged under the same viewing condition. Of the six correlations ("long," "short," and "control," with vertex or center fixation), only two proved to be significant. Since only one of these two was derived from a condition involving a $M-L$ figure rather than a control figure ( $r=.62, p=.01$, for observation of the "short" figure with center fixation), this also suggests the independence of perceived position and extent in $\mathrm{M}-\mathrm{L}$ figures. In general, then, the results of Experiment 2 show that there are errors in localizing the vertices of $M-L$ figures, but that these errors are significantly smaller than those obtained in estimation of shaft extents.

At least two problems are raised by these results. The first concerns the marked difference between the results of this experiment and those of the first experiment. Why did the first experiment produce no evidence of vertex mislocalization, whereas the second experiment did? We think that the answer to this question may lie in the differences in the pointing tasks in the two experiments, and we have therefore postponed a full discussion of this matter until the concluding discussion section. The other 
problem concerns the interpretation of the predicted finding that fixation position is a factor in the accuracy of vertex localization in M-L figures.

The original reason for manipulating fixation position in the second experiment stemmed from reports that anything that facilitated the isolation of fins from shaft was likely to reduce the illusion. We speculated that the failure to find consistent position errors in the first experiment might have resulted from fixation upon and consequent isolation of the vertex to be marked. We thought that if this had occurred, it might have so reduced the position distortions produced by $\mathbf{M}-\mathrm{L}$ figures that the normal variability in open-loop pointing might have masked them. While the results of Experiment 2 appear to support this inference, they too are also amenable to an alternative explanation.

In addition to the evidence indicating that factors that enhance the segregation of fins from shaft decrease the illusion, there was also evidence that increases in image blur increase the illusion. [The reader is again referred to Coren \& Girgus (1978, pp. 80-84) for a review of this evidence.] Thus, it seemed possible that the increase in vertex position distortion that occurs when the centers of $\mathrm{M}-\mathrm{L}$ figures are fixated might be the consequence of the loss of acuity and consequent increase in vertex blur when its image is not foveal. The possibility that this, rather than perceiver attitude, was responsible for the differences between vertex and center fixation was assessed in the last experiment.

\section{EXPERIMENT 3}

The display and procedures of this experiment were identical to those of Experiment 2, except that vertex fixation trials were eliminated and replaced by trials in which fixation was directed to a point outside the figure and beyond the vertex. If a loss in vertex acuity rather than shaft/fin segregation was responsible for the difference between center and vertex fixation, then there should be no difference between fixating center and fixating a point outside the figure, which causes the vertex to be equally peripheral. On the other hand, if the difference between vertex and center fixation was due primarily to segregation of fins and shaft, then fixating beyond the vertex and outside the figure might conceivably also result in greater vertex isolation, relative at least to center fixation. Were this the case, we should again expect larger distortions of position with center fixation. However, even if this latter speculation was incorrect, finding no difference between these two fixation positions would strongly suggest that vertex acuity was a factor in the difference between center and vertex fixation found in Experiment 2.

\section{Method}

Subjects. Ten observers with normal or corrected-to-normal vision were paid for their participation. They were unfamiliar with M-L experiments.

Display and Procedures. With the exception mentioned above, the display and procedure were the same as those used in the second experiment. Both vertex-marking and extent-estimating trials were run with fixation either at the center of the figure (thus $3 \mathrm{~cm}$ from either vertex) or $3 \mathrm{~cm}$ beyond the vertex to be marked and in line with it.

\section{Results}

Table 4 presents the obtained mean deviations from accurate pointing when the center was fixated and when a point beyond the vertex was fixated for all three stimulus types. A two-way ANOVA, in which fixation position and stimulus types were the main factors, indicated that both main effects were significant [for stimulus type, $F(2,18)$ $=29.7, \mathrm{p}<.001$; for fixation position, $\mathrm{F}(2,18)=6.29$, $\mathrm{p}<.01]$. The interaction between these factors, however, was not significant $[\mathrm{F}(4,36)=.96]$, which means that there was no difference between the effect of fixation location on the illusion and control figures. Regardless of figure type, average deviations from accuracy were greater when the center was fixated than when the point outside the figure was fixated. Although the reason for this is not clear, the fact that fixation position did not have a greater effect on the illusion than on the control figures is consistent with the speculation that the difference between vertex and center fixation found in Experiment 2 was largely a function of differences in vertex acuity rather than in perceptual, fin-isolating attitudes.

Figure 4 presents the calculated mean percent illusion derived from the extent and the inferred-extent data obtained with center and outside fixation. Extents were inferred in the same way as in the previous experiment. Like the ANOVA of the pointing data, the three-way ANOVA of the extent and inferred-extent data in which stimulus type, task, and fixation position were the main factors failed to reveal a significant interaction between fixation position and stimulus type, which again supports the inference that there were no predictable or consistent differences dependent on where the observer looked in either pointing or judging extent. This is consistent with the view that the differences between center and vertex fixation in Experiment 2 were a function of blur induced by an acuity loss rather than perceptual attitude. As expected, the

Table 4

Mean Deviations (in Centimeters) from Accurate Pointing to Figure Vertices as a Function of Stimulus Type and Fixation Position

\begin{tabular}{|c|c|c|c|c|c|c|}
\hline \multirow[b]{3}{*}{ Fixation Position } & \multicolumn{6}{|c|}{ Stimulus Type } \\
\hline & \multicolumn{2}{|c|}{$\begin{array}{l}\text { Short } \\
\leftrightarrow\end{array}$} & \multicolumn{2}{|c|}{$\underset{>}{\text { Long }}$} & \multicolumn{2}{|c|}{ Control } \\
\hline & $\begin{array}{c}\text { Left } \\
\text { Vertex }\end{array}$ & $\begin{array}{c}\text { Right } \\
\text { Vertex }\end{array}$ & $\begin{array}{c}\text { Left } \\
\text { Vertex }\end{array}$ & $\begin{array}{c}\text { Right } \\
\text { Vertex }\end{array}$ & $\begin{array}{c}\text { Left } \\
\text { Vertex }\end{array}$ & $\begin{array}{c}\text { Right } \\
\text { Vertex }\end{array}$ \\
\hline Center & $\begin{array}{l}-.32 \\
(.31)\end{array}$ & $\begin{array}{l}-.48 \\
(.39)\end{array}$ & $\begin{array}{l}-.15 \\
(.34)\end{array}$ & $\begin{array}{l}-.06 \\
(.37)\end{array}$ & $\begin{array}{l}-.05 \\
(.34)\end{array}$ & $\begin{array}{l}-.11 \\
(.39)\end{array}$ \\
\hline Beyond Vertex & $\begin{array}{l}-.11 \\
(.27)\end{array}$ & $\begin{array}{l}-.22 \\
(.55)\end{array}$ & $\begin{array}{l}-.18 \\
(.28)\end{array}$ & $\begin{array}{l}-.14 \\
(.34)\end{array}$ & $\begin{array}{l}-.05 \\
(.31)\end{array}$ & $\begin{array}{l}-.23 \\
(.34)\end{array}$ \\
\hline
\end{tabular}

Note-Standard deviations are in parentheses. - indicates deviations beyond figures, e.g., $-\longleftrightarrow-$. 


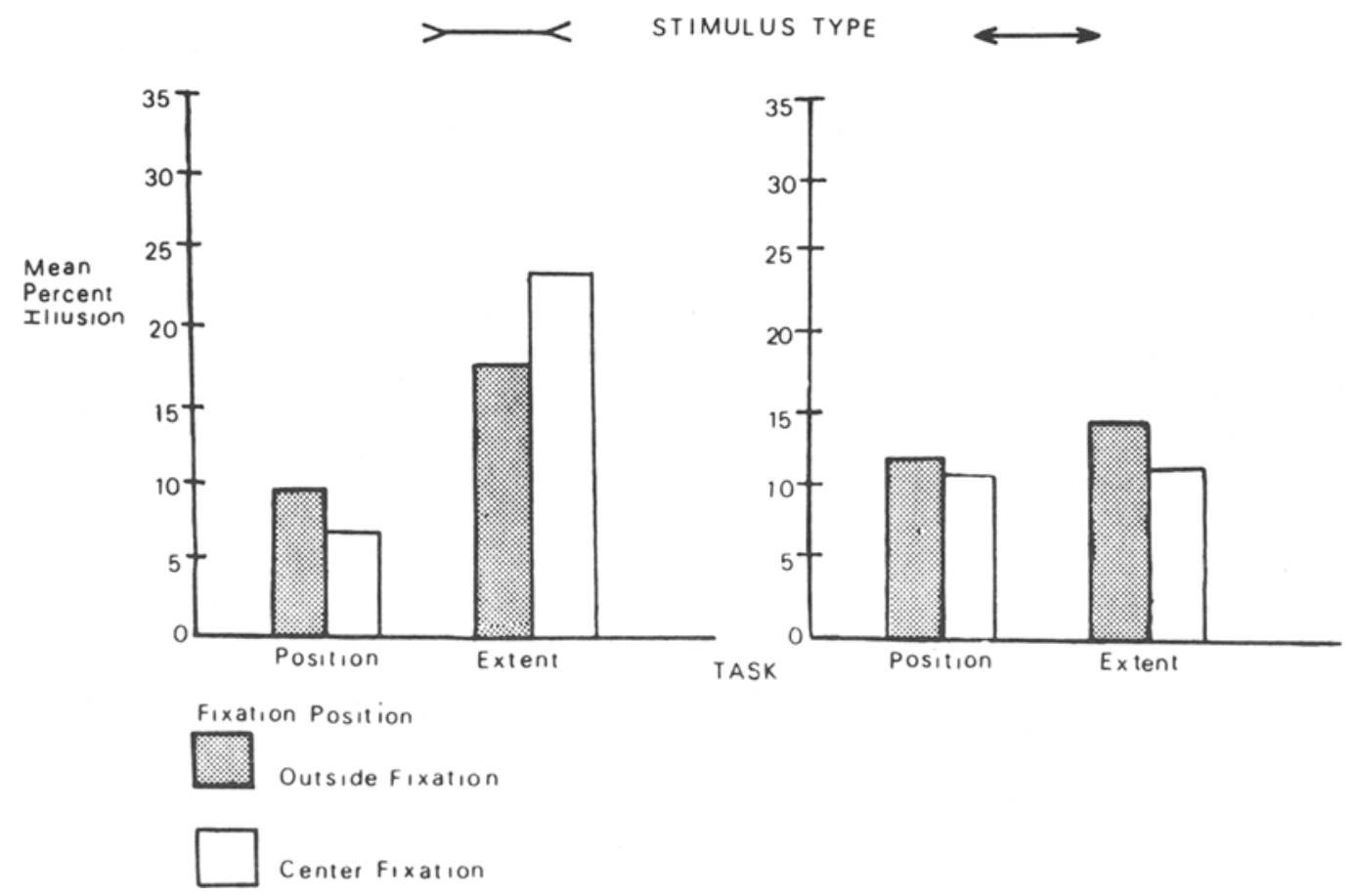

Figure 4. Mean percent illusion as a function of fixation position and task in Experiment 3.

ANOVA also produced a significant main effect of stimulus type $[F(2,18)=26.2, p<.001]$, as well as a significant interaction between task and stimulus type $[F(2,18)=12.2, p<.001]$. Thus, predictable differences between illusion and control figures were again obtained with pointing and with judging extent, and, as in Experiment 2, these differences were significantly greater in the extent judgment condition. In both experiments, the location of vertex position and shaft extent were predictably distorted by the M-L figures, but although the directions of the distortions were comparable, their magnitudes were not.

\section{DISCUSSION}

The principal question these studies sought to answer was whether there was a misperception of the position of the intersections of shaft and fins in M-L figures and, if there was, whether it was commensurate with the misperception of shaft extents. The three studies have provided an equivocal yes-and-no answer to the first question and an unequivocal "no" answer to the second. The results of Experiment 1 suggest that there are no systematic distortions of vertex positions in M-L figures, whereas the results of the subsequent two experiments suggest that there are, but that the total distortion is much less than the distortion of shaft extent.

\section{Pointing to Present and Absent Targets}

Some explanation must be found for why these experiments produced such different answers to the first ques- tion. Although we are not certain, we think that the explanation lies in the difference between the pointing tasks in the initial and subsequent experiments. In Experiment 1 , the observer pointed with his or her unseen hand to the visible intersection of shaft and fins, and did so quite accurately, or at least without making consistent errors. In Experiments 2 and 3, the observer marked the intersection of shaft and fins after the figure had been removed from view, but with his or her hand visible. Under these conditions, we found small, but consistent, distortions of position. We think that the critical factor that may account for these different outcomes may be the visible presence or absence of the pointing target, since this factor seems to be central in the control of eye movements and there is some reason to believe that there may be important similarities between the control of these two kinds of orienting responses.

Eye movements to a visible target appear to be unaffected by its perceived position. Rather, these eye movements seem to be governed either by retinal-position information or by the conjunction of this information with information about eye position, which may, but need not, determine perceived position (Hallett \& Lightstone, 1976a, 1976b; Holtzman, Sedgwick, \& Festinger, 1978; Mack, Fendrich, \& Chambers, 1982; Mack, Fendrich, \& Wong, 1982; Ono \& Nakamizo, 1977; Wong \& Mack, 1981). If the control of pointing is, in fact, like the control of eye movements, then we should not expect pointing responses in Experiment 1, where there was a visible target, to be affected by the perceived position of that target (assuming that its perceived position is discrepant with 
its position specified by either retinal or retinal and eyeposition information). Since there is no reason to suspect any misinformation about the position of the eye, which we assume was accurately fixating the target vertex, and any distortion of retinal image position should have been minimized by foveal imaging, any remaining imageposition distortion was likely to have been too small to have been reflected by open-loop pointing. (Imageposition distortion due to loss of acuity for the vertex should have been minimal with foveation of the vertex.) Thus, pointing should have shown no consistent distortion.

If pointing responses are like eye movements, however, a different outcome would be expected in Experiments 2 and 3 , where observers pointed to targets that were no longer visible, since the evidence indicates that eye movements to targets that are not contemporaneously visible are affected by their perceived positions (Holtzman et al., 1978; Mack, Fendrich, \& Chambers, 1982; Mack, Fendrich, \& Wong, 1982). Thus, if M-L figures were to engender a misperception of vertex position, this should affect the pointing responses in these two experiments. The fact that we found systematic distortions of vertex positions in Experiments 2 and 3 but not in Experiment 1 may thus be because perceived position influenced responses only in the latter two experiments. Finding significant distortions of vertex positions even with vertex fixation, where retinal image distortions were likely to have been too small to have been reflected by the open-loop pointing, is, with this analysis, particularly persuasive evidence of some perceived distortion of position. If, as Ward and Coren (1976) suggest, retinal image blur enhances the $M$ $L$ illusion, then the increase in position distortions obtained with center fixation, which the results of Experiment 3 suggest is due to loss of acuity, is also consistent with this analysis. This increase in the distortion of perceived position should have, and apparently did, influence the pointing responses.

Although this proposed account is based only on an assumed similarity between the control of eye movements and pointing, there is some evidence to suggest that it is not an unreasonable assumption. For example, Hansen (1979) found that subjects were able to accurately strike a target with a hammer even when the target was presented during an interval in which a moving stimulus was tracked and the target's position consequently misperceived. Bridgeman, Kirch, and Sperling (1981) report that observers can point accurately to a target that appears to step when it, in fact, is stationary or appears stationary when it, in fact, has stepped. Finally, Bridgeman, Lewis, Heit and Nagle (1979) report that observers can point accurately to a target that is displaced near the time of a saccade even when saccadic suppression leads its displacement to go undetected. None of this is, of course, conclusive evidence, but it is suggestive.

\section{Independence of Position and Extent}

Our results clearly show that when there is a distortion of vertex position in $\mathrm{M}-\mathrm{L}$ figures, it is not commensurate with the distortions of shaft extent. The distortions of position were much smaller than the distortions of shaft extents, even with center and outside fixations that maximized the distortions. The largest perceived illusion obtained from position was $15 \%$, whereas the largest perceived illusion when extent was judged was just about twice as large. We have thus obtained the apparently counterinuitive finding that, although the distance between outgoing fins may appear to be $30 \%$ larger than it actually is, the positions that define this distance are much more accurately perceived. Perceived position and extent must therefore be independent of each other, at least in M-L figures.

Finally, finding that there is only a small misperception of the positions of the intersections of fins and shafts in M-L figures relative to the misperception of shaft extent has relevance for the various explanations of this illusion. For example, it is completely consistent with the view that the illusion cannot be solely a function of optical blur or neural displacement of angles (Coren \& $\mathrm{Gi}$ rus, 1978), since, had this been the case, the position distortions would have been fully commensurate with the perceived distortion of extent. In fact, these results would appear to be inconsistent with any account of the illusion that either tacitly or explicitly assumes that the misperception of the position of the intersections of shaft and fins is equivalent to the misperception of the distance between the fins. Since, if we are correct, this assumption is made by all accounts of the illusion, these results must be considered inconsistent with all available attempts to explain this illusion.

\section{REFERENCES}

Benussi, V. (1904). Zur Psychologie des Gestalterfassens (die MüllerLyersche Figur). In A. Meinong (Ed.), Untersuchungen zur Gegenstands Theorie und Psychologie. Leipzig: Johann Ambrosius Burth. Benussi, V. (1912). Stroboskopische Scheinbewegungen und geometrischoptische Gestalttäuschungen. Archiv für dei Gesamte Psychologie, 24, 31-62.

BOYCE, R. P., WEST, D. C. (1967). A perceptual effect on the control of fixation. Optica Acta, 14, 119-126.

Bridgeman, B., KIRCh, M., \& SPERLING, A. (1981). Segregation of cognitive and motor aspects of visual function using induced motion. Perception \& Psychophysics, 29, 336-342.

Bridgeman, B., Lewis, S., Heit, G., \& Nagle, M. (1979). Relation between cognitive and motor oriented systems of visual position perception. Journal of Experimental Psychology, 5, 692-700.

Coren, S., * GiRgus, J. (1978). Seeing is deceiving: The psychology of visual illusions. Hillsdale, NJ: Erlbaum.

COREN, S., \& Porac, C. (1983). The creation and reversal of the MüllerLyer illusion through attentional manipulation. Perception, 12, 49-54.

Day, R. H., Bellamy, S., Norman, A. (1983). On the Morinaga misalignment illusion. Journal of Experimental Psychology: Human Perception and Performance, 9, 113-125.

DelabARRE, E. B. (1897). A method of recording eye movements. American Journal of Psychology, 9, 572-574.

DeSisto, M. M., \& Moses, F. L. (1968). Saccadic eye-movement response to Müller-Lyer stimuli. Paper presented at the meeting of the Eastern Psychological Association, Washington, DC.

Festinger, L., White, C. W., \& Allyn, M. R. (1968). Eye move- 
ments and decrement in the Müller-Lyer illusion. Perception \& Psychophysics, 3, 376-382.

Hallett, P. E., \& Lightstone, A. D. (1976a). Saccadic eye movements towards stimuli triggered by prior saccades. Vision Research, 16, 99-106.

Hallett, P. E., \& Lightstone, A. D. (1976b). Saccadic eye movement to flashed targets. Vision Research, 16, 107-114.

HANSEN, R. (1979). Spatial localization during pursuit eye movements. Vision Research, 19, 1213-1221.

Holtzman, J., SEDGWick, H., \& Festinger, L. (1978). Interaction of peripherally monitored and unmonitored efferent commands for smooth pursuit eye movements. Vision Research, 18, 1545-1555.

JudD, C. H. (1898). An optical illusion. Psychological Review, 5, 286-294.

JuDD, C. H. (1899). A study of geometrical illusions. Psychological Review, 6, 241-261.

JUDd, C. H. (1905). The Müller-Lyer illusion. Psychological Review Monograph Supplement, 7, No. 29, 55-82.

Mack, A., Fendrich, R., \& Chambers, D. (1982). Retinal and perceptual location in saccadic control. Supplement to Investigative Ophthalmology and Visual Science, 22, 104.

MACK, A., FENDRICH, R., \& WoNG, E. (1982). Is perceived motion a stimulus for smooth pursuit? Vision Research, 22, 77-88.

MorinagA, S. (1941). Some considerations on the explanation of the Müller-Lyer illusion. Japanese Journal of Psychology, 16, 26-39.

Morinaga, S., \& IKeDA, H. (1965). Paradox in displacement in geometrical illusion and the problem of dimensions. A contribution to the study of space perception. Japanese Joumal of Psychology, 36, 231-238.

Ono, H., \& Nakamizo, S. (1977). Saccadic eye movements during changes in fixation to stimuli at different distances. Vision Research, 17, 233-238.

RESTLE, F. (1976). Morinaga's paradox and figure-ground organization. Perception \& Psychophysics, 20, 133-156.

Rock, I. (1966). The nature of perceptual adaptation. New York: Basic Books.

Rock, I. (1984). Perception. New York: Scientific American Library.
Stratton, G. M. (1906). Symmetry, linear illusions and the movements of the eye. Psychological Review, 13, 81-96.

WARD, L. M., \& CoREN, S. (1976). The effect of optically induced blur on the magnitude of the Müller-Lyer illusion. Bulletin of the Psychonomic Society, 7, 483-484.

WONG, E. (1981). Information used by the oculomotor system in saccadic programming and the relationship of perceptual and saccadic responses. Unpublished doctoral dissertation, New School for Social Research.

WoNG, E., \& MACK, A. (1981). Saccadic programming and perceived location. Acta Psychologica, 48, 123-131.

YARBus, A. L. (1967). Eye movements and vision. New York: Plenum Press.

\section{NOTES}

1. When accuracy was stressed, observers were told, "Your task is to shift your fixation as accurately as possible from one vertex to another. Try to make one eye movement in shifting your fixation." When the alternate instructions were given, observers were asked to "look from one vertex to another. Scan the display using the vertices as the start and end positions of your scanning. Try to make a single scan each time you shift your fixation" (Wong, 1981, p. 59).

2. Data relevant to saccades suggest that perceived position may exert an influence over saccades only when the position of the target to which the eye is moving is remembered (Mack, Fendrich, \& Chambers, 1982).

3. If an observer were allowed to see his or her pointing hand and the figure simultaneously, he or she could have simply aligned one with the other, and this would have failed to indicate whether or not the target vertex was mislocalized. In order to avoid this version of the El Greco effect (Rock, 1966), either the pointing hand or the figure was not present during the pointing task.

(Manuscript received October 9, 1984; revision accepted for publication February 20, 1985). 